\title{
E-HEALTH: LEGAL AND SECURITY CHALLENGES
}

\author{
Gabriela BELOVA, Stanislav PAVLOV \\ "Neofit Rilsky" South-West University, Blagoevgrad, Bulgaria \\ gabrielabelova@gmail.com
}

\begin{abstract}
In accordance with the National Security Strategy of the Republic of Bulgaria, updated in 2018, the health of Bulgarian citizens is defined as a vital national interest. The analysis of the data on basic health-demographic indicators shows that our country is currently facing significant national security risks associated with a high level of total and premature mortality, high maternal and infant mortality, high level of disability and low life expectancy, as well as low indicators during the years of good health. The authors consider that improving the health of the nation is inextricably linked to the readiness of the national health system to respond and to provide adequate and continuous medical assistance of good quality. One of the major challenges for the contemporary globalized world is the rapid entering of information and communication technologies in healthcare. The article attempts to outline some of the legal and ethical issues that could arise when information and communication technologies are introduced into the healthcare system (e.g. the use of various applications for mobile devices, remote therapy and disease monitoring, etc.) from a point of view human rights doctrine and the protection of personal data.
\end{abstract}

\section{Keywords: e-health, human rights, data protection}

\section{Introduction}

One of the major challenges for the contemporary globalized world is the rapid entering of information and communication technologies in healthcare. In the 1990s, with the appearance of the Internet, a number of terms were emerging, including the definition of 'electronic', similarly the term 'e-health', which binds information and communication technologies to improving the health system.

According to the definition of the World Health Organization (WHO), e-health is the use of information and communication technologies for the purposes of healthcare [1]. The European Commission adheres to a definition that makes the actual use of the term more equitable. It defines 'e-health' as referring to all resources based on information and communication technologies that can support and improve the prevention, diagnosis and treatment of diseases as well as health surveillance and management [2]. The entering of information and communication technologies when providing and accepting the healthcare services and the sharing of health information inevitably raises some issues of a legal, security and ethical nature.

\section{Privacy and integrity as a human right} The privacy of the human being as one of the fundamental human rights is enshrined in all international instruments - the Universal Declaration of Human Rights of 1948, the International Covenant on Civil and Political Rights of 1966, the European Convention for the Protection of Human Rights and Fundamental Freedoms 1950, etc., albeit in a slightly different context. 
The Charter of Fundamental Rights of the European Union, as a document proclaimed at the beginning of the new millennium, in Art. 3, explicitly defines privacy more as the right to respect someone's physical and mental (psychological) integrity.

Moreover, paragraph 2 of the same provision emphasizes the importance of this right in the field of medicine and biology, where there 'must be respected in particular:

(a) the free and informed consent of the person concerned in accordance with statutory terms and conditions;

(b) the prohibition of eugenic practices, particularly those aimed at the selection of people;

(c) the prohibition of making the human body and its parts a source of profit; (d) the prohibition of the reproductive cloning of human beings'.

The problem of the ageing population in the European Union also stimulates the development of smart devices, sensors and applications for mobile phones in the healthcare sector. EU citizens live longer often well above retirement age, but the average age at which they are in good health remains the same. This leads to pressure on society and the economy as well as on health systems. The morbidity of some diseases, such as Alzheimer's and dementia, is also rising as the population ages. The European Union seeks to achieve by 2020 a 2 -year increase in healthy years of life so that Europeans can remain active and productive for as long as possible.

The use of the Internet of things in healthcare through the so-called smart devices, RFIDs, sensors, cameras, mobile phone applications undoubtedly could significantly improve the effectiveness of locating patients suffering from dementia or Alzheimer's; to allow remote monitoring of patients with chronic diseases such as diabetes or cardiovascular disorders with behavioral changes due to anorexia, smoking, etc. Therefore, the Regulation (EU) $2017 / 745$ for medical devices was adopted in the European Union in April 2017, which will apply from 26 May 2020.

Respect for patient's integrity is a fundamental ethical principle for all health care, including e-health, and this should be taken into account, especially where IT is used in the form of so-called 'assistive technologies', such as for elderly people or people with special disabilities. The use of such devices, such as fall detectors, for example, on the one hand, could provide peace of mind to the staff and/or relatives, but on the other hand, some patients may feel threatened. Some patients may consider their personal integrity and human dignity to be at risk from new technologies and electronic devices, especially if there is a series of falls during continuous monitoring. Not all elderly people would probably want other people to know they have fallen, as this is also related to the more serious question of whether they are capable of caring for themselves and, more broadly, their ability to act.

In this sense, recourse to such technologies and devices should be tested even for a certain period of time and accepted by the patient, otherwise, they could use standard services such as visits to medical professionals. In some cases, elderly people may feel that their inviolability is endangered if they are not given the opportunity to make their own decisions and to take responsibility. The design of such devices should prevent the patient from becoming dependent on technology and stimulate more active patient involvement in their own treatment.

The use of assistive technologies may be a challenge to the privacy of elderly people, but the information transmitted by the device in a majority of cases does not differ significantly from the alert systems used in hospitals or social services in some countries. In this sense, consideration of the elderly's view of monitoring devices would contribute to a better balance between the needs of treatment and the privacy of their privacy. 
E-health applications can reduce health care costs, increase patient access to improved quality of health services, ensure health care continuity, and reduce patients' loss of working time, travel and cash. They can also increase patients' satisfaction and provide a sense of security for patients with chronic illnesses to increase their autonomy. Time factor and geographical constraints are most common among the reasons that lead to the use of e-health applications as part of the treatment. Although e-health applications have major potential in the field of medicine and health, some researchers are warning of the possibility of becoming prisoners of our own technology [4]. This means that electronic applications should not prevent people from attending healthcare professionals in person if they wish to do so. One of the most dangerous consequences of an IT revolution would be if, in the end, individuals lose their personal choices about what health services they want to get. The lack of human touch is a significant disadvantage in e-health applications. Therapeutic touch is a very important part of the treatment and cannot be achieved in cases where the patient and the healthcare professional are not in the same place. This fact also supports the idea that e-health applications should be used to support traditional health care rather than as an absolute substitute to it.

\section{E-health and data protection}

The protection of personal data as a consequence of respect for privacy also appears later in the legal framework as an independent right. Within the EU, Art. 8 of EU Charter of fundamental rights is dedicated to the protection of personal data, as well as Art. 16 TFEU and, above all, the new provisions contained in the General Regulation on the protection of personal data (Regulation (EC) 2016/679) [5]. It is particularly important to comply with the rules on the collection, processing, storage and disclosure of personally identifiable information in order to prevent violations of the right to the protection of personal data. The General Regulation prohibits the processing of these types of health data unless one of the following three conditions applies: the data subject must have given explicit consent; processing is necessary for the purposes of preventive or occupational medicine, assessment of employees, medical diagnosis, provision of health or social care or treatment, or the management of health or social systems and services; processing is necessary for reasons of public interest in the field of public health such as protection against serious cross-border health threats or providing of high standards of quality and safety of healthcare and of medicinal products or medical devices.

In this sense, patients have the right to control the use and dissemination of their personal data representing health information and to choose the best e-health application as there is still some degree of uncertainty in all telecommunication systems [6]. When using e-health applications that provide direct communication with the patient, the healthcare professional should always first make sure that the person he is talking to is the patient, for example, during telephone consultations. He also needs to make sure that the conversation with the patient cannot be overheard by others. If the patient is not alone or using a microphone, he/she needs to be informed that his/her privacy could be endangered. The use of telepsychiatry, for example, would create a situation where there are others present in the session and poses a challenge to ehealth applications.

In addition, confidentiality is historically seen as a basic principle of medical ethics, which means that the doctor or other healthcare professionals should keep the information about his patient even after his death. Any personal information should not be disclosed without the patient's permission, which in turn ensures that the patient will trust and inform healthcare professionals about matters affecting his treatment. 
The general regulation on personal data protection goes even further, distinguishing apart from data on the health of the person, two more types of data: genetic and biometric. The three data sets may be processed provided that one of the conditions provided for in Article 9 (2) of the Regulation (EC) $2016 / 679$ is in place. In addition, Member States have additional conditions or restrictions with regard to the processing of genetic, biometric and human health data.

In this sense, information integrity should not be confused with confidentiality in the relationship between the doctor and the patient. It is part of internationally recognized inviolability as a fundamental human right. The privacy of the person as a first-generation right is formed after the Great French Revolution and is proclaimed in the Universal Declaration of Human Rights of 1948, the International Covenant on Civil and Political Rights of 1966 and others. In contrast, confidentiality in physician-patient relationships is as old as medicine itself, and at least we could trace it to the times of Hippocrates. Of course, ehealth has a definite impact on confidentiality, but in any case, it should not be confused with the privacy of the person. Sometimes it is difficult to separate them because if the healthcare provider violates the confidentiality, this would almost always lead to a violation of the patient's information integrity. Consequently, according to some authors, confidentiality falls entirely within the context of the right of access to health care [7]. Equal access to health goods, services and care as a basic human right is the ultimate interest that confidentiality serves, interest not only of the individual but also of society as a whole. The same can hardly be said in terms of information integrity.

\section{Electronic healthcare in Bulgaria}

A good example of a country that is currently undergoing a substantial change in its healthcare system, is Bulgaria. In accordance with the National Security Strategy of the Republic of Bulgaria, updated in 2018, the health of Bulgarian citizens is defined as a vital national interest. The analysis of the data on basic health-demographic indicators shows that our country is currently facing significant national security risks associated with a high level of total and premature mortality, high maternal and infant mortality, high level of disability and low life expectancy, as well as low indicators during the years of good health [9]. The document considers that improving the health of the nation is inextricably linked to the readiness of the national health system to respond and to provide adequate and continuous medical assistance of good quality despite some risks as the geographical situation of the Republic of Bulgaria predetermines a constant flow of illegal migrants to our borders. The development of these processes outlines a number of risks to our national security in economic, health and social terms.

Unfortunately, the considerable increase of the financial resource for the healthcare sector does not lead to significant changes in the observed and previous periods of regressive trends in the public health sphere. The ineffective organization of the health system is the main reason for generating offenses in this area. A problem continues to be the 'draining' of the National Health Insurance Fund through misuse of the clinical paths [10].

Leaving of young and qualified specialists to higher wage countries is a prerequisite for increasing staff shortages and serious problems in delivering quality health care. Thus, without young medical professionals, the implementation of modern information technology in medical practice is questionable. In Bulgaria, the rise of the physicians' age is proportional to the lack of experience of using computers in their practice. In order to assess the actual necessity of education for using electronic healthcare system, a study has been carried 
out among the physicians in the country. The study covered about $5 \%$ of the physicians in Bulgaria and reveals that about $68 \%$ of them do not have computers in their offices and about $1 \%$ are not keen on using one [11]. Nevertheless, over $90 \%$ of participants demonstrated the will to be educated on how to use computers to their and the patients' advantage [12]. A similar percentage of respondents showed a positive attitude towards the implementation of electronic medical data and consider that the paper-based medical records are not suitable for organising the medical data of patients nowadays.

\section{Conclusion}

In conclusion, e-health is the use of information and communication technologies for the needs of healthcare, namely the discovery of diseases, the treatment of patients, the training of medical specialists, the monitoring of public health trends, etc. The international community and the national governments should take it into account and use its advantages for the reform of the system in terms of wider access to healthcare, and promote further economic and social development.

[1] http://www.who.int/ehealth/about/en/

[2] https://ec.europa.eu/health/ehealth/policy_en.

[3] Draper H, Sorell T. Telecare, remote monitoring and care. Bioethics 2012.

[4] Stanberry B. Telemedicine: barriers and opportunities in the 21st century. Journal of Internal Medicine 2000;247(6):615-28.

[5] Белова Г., Марин Н., Георгиева Г., Кочев Й. Нови моменти в защитата на личните данни в Европейския съюз, Научни трудове на Института за държавата и правото, т. XVI, БАН ИДП, София, 2017, с. 54-65.

[6] Chankova D., Voinova R. Towards New European Regulation for Handling Electronic Evidence, US-China Law Review, March 2018, Vol.15, No. 3, pp. 121-129. See also Ivanova A. The impact of the case-law of the Court of Justice of the European Union in the field of public procurement, De Gruyter Open, KBO Conference Proceedings, Vol. XXIV, Issue 2, 2018, pp. 189-193.

[7] Buijsen, Martin EHealth: Its Impact on Patients Rights and Medical Confidentiality, in: Medicine, Law and the Internet, Nomiki Bibliothiki S.A. Athens, 2018, pp.83-93.

[8] Chankova D., Georgieva G. Security and Human Rights: Contradictory or Reconcilable Paradigms? State of Affairs in Bulgaria, De Gruyter Open,Vol. XXII, KBO Conference Proceedings No 2, Nicolae Balcesku Land ForceAcademy Publishing House, 2016, pp.83-88.

[9] Актуализирана стратегия за национална сигурност на Република България, приета с Решение на НС от 14.03.2018 г.,обн., ДВ, бр. 26 от 23.03.2018 г.

[10] Ibidem.

[11] Feshieva N., Mircheva I. Proofs of the necessity of medical informatics for the physicians in Bulgaria. Studies in health technology and informatics 2001 (2), pp.1019-1022.

[12] Karadzhova-Manova M. The Necessity of Electronic Healthcare in developing European countries, in: Medicine, Law and the Internet, Nomiki Bibliothiki S.A. Athens, 2018, pp.374-378. 